Clowes, R. C. \& Rowley, D. (1955). J. gen. Microbiol. 13, 461-473

\title{
Genetic Studies on Small-colony Variants of Escherichia coli K-12
}

\author{
By R. C. ClOWES AND D. ROWLEY \\ The Wright-Fleming Institute of Microbiology, St Mary's Hospital \\ Medical School, London, W. 2
}

\begin{abstract}
SUMMARY : Stable small-colony variants of Escherichia coli K-12 and several of its auxotrophs were isolated by treatment of cultures with copper sulphate solutions. These variants did not show any associated changes in nutritional, fermentative or serological characters. The small-colony forms showed normal recombining character in two instances, but in one variant the $\mathrm{F}$ - form showed a lower recombination rate and atypical transfer of markers. However, when rendered $F+$ this variant behaved in a manner analogous to the normal $\mathrm{F}+$ parent strain. The results have been interpreted as evidence that the small-colony character can arise by a nuclear mutation at one of several possible genetic loci.
\end{abstract}

The isolation of variants which differed from the parent strains by exhibiting a smaller colonial size on solid media has been reported by many authors (Braun, 1947) from a variety of species of bacteria. Most variants were isolated from unfavourable environments produced by antibiotics, toxic inorganic salts or by ageing, and in many instances concomitant changes were found in nutritional requirements, fermentative capacities and serological types. Kuhn \& Sternberg (1931) showed that small-colony variants (SCVs) could readily be isolated from a variety of widely differing bacterial species by the use either of ammonia or by transient exposure to phenol. Interest in these small- or 'dwarf'-colony variants was greatly stimulated in 1931 by the report by Hadley, Delves \& Klimek that small-colony variants isolated from Shigella spp. by the use of lithium chloride passed through bacteriological filters. It was suggested by these authors that the variants represented a stage in the development cycle of the vegetative growth of the bacterium for which the term 'gonidial' or $\mathbf{G}$ form was proposed. Moreover, these $\mathbf{G}$ forms were reported to differ in nutritional, fermentative and serological properties from the original strain. Also using $\mathrm{LiCl}$, Swingle $(1934,1935)$ isolated small colonies from Staphylococcus aureus, but she was unable to demonstrate the filterability of these variants. Although they had apparently lost certain fermentative capacities, they were antigenically unchanged. The loss in fermentation capacity was verified by Youmans (1937) by the use of the same salt on $S$. aureus. He suggested that these loss variations were due to an overall lowering of the metabolic rate of the small-colony variants, produced in response to the inhibitory environment. By the use of 2-methyl-1 : 4-naphthoquinone (menaphthone) Colwell (1946) was able to isolate stable smallcolony variants of Escherichia coli which resembled those of Staphylococcus aureus already reported, both in their frequent reversion to normal size in 
liquid media and also by their loss of certain fermentation capacities. Voureka (1951), by the use of chloramphenicol and specific antiserum, isolated from Escherichia coli a small-colony variant which differed from the parent strain only in its antibiotic sensitivities. Manten \& Rowley (1953) produced small colony variants of $\boldsymbol{E}$. coli by the use of chloramphenicol and normal serum, and showed that in most instances no change had arisen in any other character. When Staphylococcus aureus was treated with the same antibiotic under conditions which excluded the selection of spontaneous mutants (Voureka, 1952), dwarf variants were produced. The decrease in colonial size was associated with losses in biochemical activities, phage sensitivities and mouse virulence but not with sensitivity to chloramphenicol. Weed \& Longfellow (1954) reported the isolation of small-colony forms of Escherichia coli after treatment with low $\left(5 \times 10^{-6} \mathrm{M}\right)$ concentrations of cupric ion, and Wise \& Spink (1954) have isolated small-colony variants from Staphylococcus aureus by the use of various antibiotics in vitro, and from human cases with a history of antibiotic therapy.

Although Youmans (1937) has suggested that loss in nutritional and fermentation characters is related to a lower metabolic rate in the small colonies, concomitant qualitative changes of serological and phage relationships reported by various authors are difficult to account for by the concept of a single gene mutation. Ephrussi (1953) showed that in Saccharomyces spp., small-colony variants, which he called 'petites', can arise as a result of a loss of cytoplasmic genetic units. It was of interest therefore to attempt to isolate small-colony forms from bacterial strains that undergo genetic recombination. Recombination studies of such variants should help to clarify certain of the conflicting hypotheses that have been proposed to account for this phenomenon (Braun, 1947).

\section{METHODS}

Bacterial strains. The K-12 strain of Escherichia coli and several of its wellinvestigated auxotrophic mutants 58-161 (requiring methionine), and W-677 (requiring threonine, leucine and thiamine) were used both for the isolation of small-colony variants and in subsequent recombinations. $\mathbf{F}+$ and $\mathbf{F}-$ types (Hayes, 1953) of streptomycin-sensitive and of streptomycin-resistant mutants of each auxotroph were used.

Minimal medium (MM) of Davis \& Mingioli (1950) was used for the isolation of small-colony variants or in some instances the basal medium of Weed \& Longfellow (1954), both supplemented with appropriate growth factors where necessary.

Nutrient media of beef digest, veal digest, blood, boiled blood and MacConkey agar were those routinely used in this Institute.

Partially-defined complete media used were those of Cohen \& Wheeler (1946) solidified with agar and with added charcoal and catalase (Mazloum \& Rowley, 1955), eosin methylene blue sugar (EMB) medium (Lederberg, 1950) solidified with either agar or silicic acid (Taylor, 1950) and a peptone Lemco Yeastrel Pronutrin (PLYP) medium quoted by Challice \& Gorrill (1954). Eosin 
methylene blue (EMB) agar (Lederberg, 1950) was used for the scoring of sugar fermentation characters.

Recombination techniques employed were the standard auxotrophic and streptomycin prototrophic techniques of Lederberg (1951), and were carried out as described previously (Clowes \& Rowley, 1954 b).

Transfer of the F + character was achieved by incubation in fresh broth $\left(10 \mathrm{ml}\right.$.) of a mixture of overnight cultures of a $\mathrm{St}^{\mathrm{B}} \mathrm{F}+\operatorname{strain}(0 \cdot 2 \mathrm{ml}$.) and a $\mathrm{St}^{\mathrm{R}} \mathrm{F}$ - strain $\left(0.01 \mathrm{ml}\right.$.) for $18 \mathrm{hr}$. at $37^{\circ}$. Subsequent plating on streptomycin nutrient agar permitted growth of the $\mathrm{St}^{\mathrm{R}}$ strain, separate colonies of which were tested for the $\mathbf{F}+$ character by mating with a complementary $\mathbf{F}-$ strain.

Sugar fermentation markers were scored on plates of EMB agar by the velveteen replica plating method of Lederberg \& Lederberg (1952). The master plate used was prepared by emulsifying the recombinant colonies in saline and inoculating on a plate of the selective medium positioned above a template.

Colonial size of the recombinants was tested in the following manner. Inocula of colonies from a replica of the recombination plate were streaked on the same nutrient agar plate as control streakings of both parents taken from cultures on solid media inoculated at the same time as the replication.

Growth curves were plotted from cultures in nutrient broth and in minimal media. Overnight cultures were diluted to give $c .100$ cells $/ \mathrm{ml}$. and incubated at $37^{\circ}$ with shaking in $10 \mathrm{ml}$. samples in bottles which could be accommodated in a Hilger photoelectric spectrometer (Spekker). Viable cell counts were made by taking samples at hourly intervals, serially diluting in saline in duplicate and inoculating $0.02 \mathrm{ml}$. drops on the surface of nutrient agar plates (Miles \& Misra, 1938). When the growth had reached visible opalescence, parallel turbidity estimations were made in the 'Spekker'.

Motility measurements were carried out by determining the penetration of a motile strain along a column of sloppy agar. The apparatus, shown in Pl. 1, fig. 1, consists of a series of capillary tubes of $1 \mathrm{~mm}$. bore and $45 \mathrm{~cm}$. long. These were drawn out at one end, which was treated with silicone, and the other end was joined to a $3 \mathrm{~cm}$. length of $4 \mathrm{~mm}$. bore soft glass tube. After heat sterilization, sterile molten nutrient agar (Difco 0.4\%) was drawn up the tube to form an uninterrupted column of agar about $35 \mathrm{~cm}$. long. A $4 \mathrm{hr}$. broth culture of the motile strain, previously passed through a Craigie tube, was diluted (1/100) and $c .0 .02 \mathrm{ml}$. inoculated to make contact with one end of the solidified sloppy agar column, which was allowed to extrude slightly from the capillary into the wider end of the tube. The inoculum was then drawn into the capillary by allowing the agar to move towards the drawn-out end, so that finally the agar column and inoculum occupied a position midway in the capillary. The tubes were incubated horizontally for $18 \mathrm{hr}$. at $37^{\circ}$. The drawn-out silicone end was then sterilized by flaming, and by means of a perforated teat the column was extruded in measured lengths into $2 \mathrm{ml}$. samples of nutrient broth. The extent of movement of the motile organism down the capillary was then found by the end-point of growth in the samples of broth after incubation. 
It was found that under standard conditions triplicate assays always gave results within $5 \mathrm{~cm}$. Young broth cultures gave the fastest speeds; these decreased with the age of the cultures, and 4-6 hr. cultures were normally used in determinations. Variation in inoculum size from $0.02 \mathrm{ml}$. of an undiluted $4 \mathrm{hr}$. broth culture down to $0.02 \mathrm{ml}$. of a culture diluted 1/1000 gave no variation in results, but further dilution below $1 / 1000$ (corresponding to $c .500$ cells) decreased the movement. Increase in agar concentration decreased movement, $0.4 \%$ being the concentration chosen to give sufficient rigidity to the agar column, whilst allowing maximum movement of fastest strains after 18-24 $\mathrm{hr}$. incubation at $37^{\circ}$. Controls of non-motile Escherichia coli B showed no movement (Furness \& Rowley, 1955).

\section{RESULTS}

\section{Isolation of small-colony variants}

Attempts to isolate stable small-colony forms of Escherichia coli K-12 or its auxotrophs by the techniques of Colwell (1946) and Voureka (1951) were without success. By the technique of Weed \& Longfellow (1954) stable variants were isolated with relative ease from all strains, although the inhibitory concentration of cupric ions was found to be higher in the case of $E$. coli K-12 $\left(10^{-4} \mathrm{M}\right)$ than with $E$. coli $\mathrm{B}\left(2.5 \times 10^{-3} \mathrm{M}\right)$. In detail the method consisted of the addition of $10^{8}$ cells of a fresh culture of the strain to $25 \mathrm{ml}$. volumes of MM medium (Davis \& Mingioli, 1950) containing copper at concentrations of $2 \times 10^{-4}, 10^{-4}, 5 \times 10^{-5}$ and $2.5 \times 10^{-5} \mathrm{M}$, which were then incubated at $37^{\circ}$. Samples were plated on nutrient agar after $24 \mathrm{hr}$. and $30 \mathrm{hr}$. The cultures at the two lowest concentrations of copper usually showed turbid growth after $24 \mathrm{hr}$., and the majority of the colonies isolated were of normal size; the culture containing $10^{-4} \mathrm{M}$ copper showed little visible turbidity but on plating, between 10 and $50 \%$ of the colonies were found to be small. From the highest concentration of copper small colonies were isolated, but the cultures were frequently sterile after $24 \mathrm{hr}$. incubation. On subculture $98-99 \%$ of all the small colonies tested reverted to the normal size, the remainder retaining the small colonial appearance. Thus two small-colonies designated K-12-1, K-12-2 were isolated in separate experiments from $E$. coli K-12 cultures in $5 \times 10^{-5} \mathrm{M}$ copper, one colony designated $\mathrm{W}-677-7$ from the incubation in $2.5 \times 10^{-5} \mathrm{M}$ copper of $\mathrm{W}-677 / \mathrm{St}^{\mathrm{R}} / \mathrm{F}$ - and two colonies $58-161 / 1$ and $58-161 / 2$ from the same culture of $58-161 / \mathrm{St}^{\mathrm{R}} / \mathrm{F}$ - in medium containing $2 \times 10^{-4} \mathrm{M}$ copper. The growth of K-12 and K-12-1 spread on the same nutrient agar plate after $18 \mathrm{hr}$. incubation at $37^{\circ}$ is illustrated in $\mathrm{Pl}$. 1, fig. 2.

\section{Properties of small-colonies}

The small-colony variants showed colonial diameters of 0.75-1.0 mm. after incubation for $18 \mathrm{hr}$. at $37^{\circ}$ on nutrient agar, as compared with a diameter of 2-3 mm. shown by the parent strains under these conditions. They may therefore be different from the relatively smaller forms isolated from Escherichia coli by Colwell (1946) and by Weed \& Longfellow (1954), whose variants had 
colonial diameters of a sixth to a tenth those of the original strains. The present small-colony variants conform to the relative size of the majority of variants isolated by Manten \& Rowley (1953) by the use of chloramphenicol and serum, and also to the 'petites' of Ephrussi(1953). In addition, the variants, without exception, resembled the parent strains in all other characters tested, including methyl-red, Vosges-Proskauer and indole reactions, sugar fermentations, sensitivities to coliphages $T_{1}$ to $T_{7}$, auxotrophic requirements and inhibitions by amino acids (Rowley, 1953); and they were agglutinated by $\boldsymbol{E}$. coli $\mathrm{K}-12$ rabbit $\mathrm{O}$ antiserum to the same titre as the parent strain (1/6400). In this way they resembled the stable variant isolated by Voureka (1951), but differed from the small colonies of $\boldsymbol{E}$. coli of Colwell (1946), Weed \& Longfellow (1954), and from those of other species investigated by many authors who found accompanying decreases in certain fermentative and synthetic activities of the original strain.

When the variants derived from $\mathrm{F}$ - strains were tested they were found to have retained the $\mathbf{F}$ - recombining character, in that they mated only with $\mathbf{F}+$ strains. They could be rendered $\mathbf{F}+$, the small colonial character being preserved.

The colonial morphology of all small-colony variants was characteristic of smooth Escherichia coli colonies of that size. Morphologically they were indistinguishable from the parent strain, although on first isolation stained smears revealed pleomorphic rods in addition to coccobacillary and coccoid forms as described by Voureka (1951). This pleomorphism was characteristic of the whole culture in the presence of inhibitory concentrations of chloramphenicol or copper.

So far we have not been able to account for the small colonial size. That lack of a growth factor was responsible seemed possible from the ability to vary the ratio of the small to normal colonial size by growth on various solid media. However, none of the media used, which included blood, boiled blood, minimal, nutrient, EMB, veal digest, PLYP and MacConkey agar, all with or without a supplement of $1 \%$ glucose, permitted the small colonies to grow to more than half the size of the colonies of the corresponding normal strain. Furthermore, on MM medium + Casamino acids, $p$-aminobenzoic acid, yeast nucleic acids, glutathione, thiamine, pantothenic acid, riboflavin, nicotinamide, or pyridoxine either individually or in various mixtures, there was no change in the relative sizes of the SCVs and parental colonies. The small-colony variants do not, therefore, appear to be deficient in certain synthetic abilities as are those variants described by Weinberg (1950) and Gillespie (1952).

The absence of a self-inhibitor such as is produced by Haemophilus pertussis (Mazloum \& Rowley, 1955), was shown by the maintenance of the small colonial size on Cohen \& Wheeler medium supplemented with charcoal and catalase. The preservation of colonial size ratios on plates of EMB medium solidified with silica gel (Taylor, 1950), indicated that an intolerance to some inhibitor present in agar was not responsible.

Lack of analogy with the 'petite' colonies isolated by Ephrussi (1953) from yeast was shown by the maintenance of the colonial size ratios under anaerobic 
conditions of growth on nutrient agar, when the colonies of both parental and small colonial strains were diminished to about a third the size of those obtained under aerobic conditions. Growth in air $+5 \%$ or $10 \%(\mathrm{v} / \mathrm{v}) \mathrm{CO}_{2}$ did not alter colony sizes, indicating that the variants did not arise by interference in the pyruvic acid decarboxylation system as was found by Hale (1951) in the case of certain G variants of Staphylococcus aureus.

Differences in colonial size in Escherichia coli have been accounted for in certain instances by variations in polysaccharide production (Wilkinson, Duguid \& Edmunds, 1954). It seemed possible that the parent and variant colonies might contain the same number of cells but of different size because of a diminished extracellular secretion of some metabolic product by the small colonies. Viable counts of whole colonies made in triplicate by the Miles \& Misra (1938) drop technique, however, indicated that the numbers of cells in the large parental colonies were 20-50 times as great as in the variants, and excluded this possibility.

Electron micrographs taken of the colonies on nutrient agar, by the "pseudoreplica' method of Hillier \& Baker (1946) on to sheets of collodion, failed to show any differences in the arrangement or packing of the cells within the colonies that might have been related to colonial size.

When small-colony variants were inoculated on plates of sloppy $(1 \%)$ nutrient agar, growth spread across the plate, and an examination, by the hanging-drop technique, of cells taken from the periphery of growth, showed the presence of motile cells. The parental strains were motile under the same conditions. However, in the case of two of the variants (K-12-1, W-677-7), the time taken to spread across the plate was longer than that taken by the parental strains, this speed of movement being a constant factor which was not altered by successive subculture from the periphery of growth. Measurements of the speeds of movement of the small-colony variants and of the parental strains were made by determinations of the penetration of the organisms along columns of $0.4 \%$ nutrient agar; the results are summarized in Table 1 . The results show that the speed of movement appears to be characteristic for each strain, and is less in the case of two of the variants (K-12-1 and W-677-7) than in the corresponding parent strains, but in one strain, 58-161/1, it is almost identical with the speed of the parent strain.

Table 1. Movement of Escherichia coli $K-12$, its auxotrophs, and small-colony variants along a $1 \mathrm{~mm}$. capillary of $0 \cdot 4 \%$ nutrient agar after incubation at $37^{\circ}$ for $18 \mathrm{hr}$.

$\begin{array}{ccccccc}\text { Strain ... } & \text { K-12 } & 58-161 & \text { W-677 } & \text { K-12-1 } & 58-161 / 1 & \text { W-677-7 } \\ \begin{array}{c}\text { Movement } \\ \text { (cm.) }\end{array} & 29 & 32 & 24 & 17 & 32 & 15 \\ & & & & & & \end{array}$

In liquid medium (either nutrient broth or minimal medium) the rates of multiplication of the small-colony variants were always less than the rates of multiplication of the corresponding normal strains. For example, in nutrient broth at $37^{\circ}$ the growth rate of Escherichia coli K-12 from an inoculum of 
c. 100 cells was characterized by a mean generation time of $20 \mathrm{~min}$. between the densities of $10^{4}$ and $10^{3}$ cells $/ \mathrm{ml}$., whereas its small-colony variant K-12-1 had a mean generation time of $25 \mathrm{~min}$. There did not appear to be any difference in the lag phases, such as occurred with the small-colony variants of Staphylococcus aureus isolated by Swingle (1935). We must conclude therefore that the reason for the difference in colonial sizes on solid media is a slower rate of multiplication of the small-colony variants.

\section{Recombination experiments}

The results of mating the small-colony variants by the standard techniques (Clowes \& Rowley, 1954a) with normal-sized colony parents of opposite mating type are shown in Table 2; Table 3 shows the corresponding results obtained from matings of normal-sized colonial parents. In the case of W-677$7 / \mathrm{St}^{\mathrm{R}} / \mathrm{F}-$ (the small-colony variant of $\mathrm{W}-677 / \mathrm{St}^{\mathrm{R}} / \mathrm{F}-$ ), when mated with $\mathrm{K}-12$ $\mathbf{F}+$ on $\mathbf{M M}$ medium + streptomycin (Table 2 , line 1), both the recombination rate and transfer of sugar fermentation markers paralleled the corresponding

Table 2. Matings of strains of Escherichia coli, one parent being a small-colony variant Recombination rate is expressed as: $\frac{\text { no. prototrophs/plate }}{\text { no. } \mathrm{F}-\text { cells/plate }}$

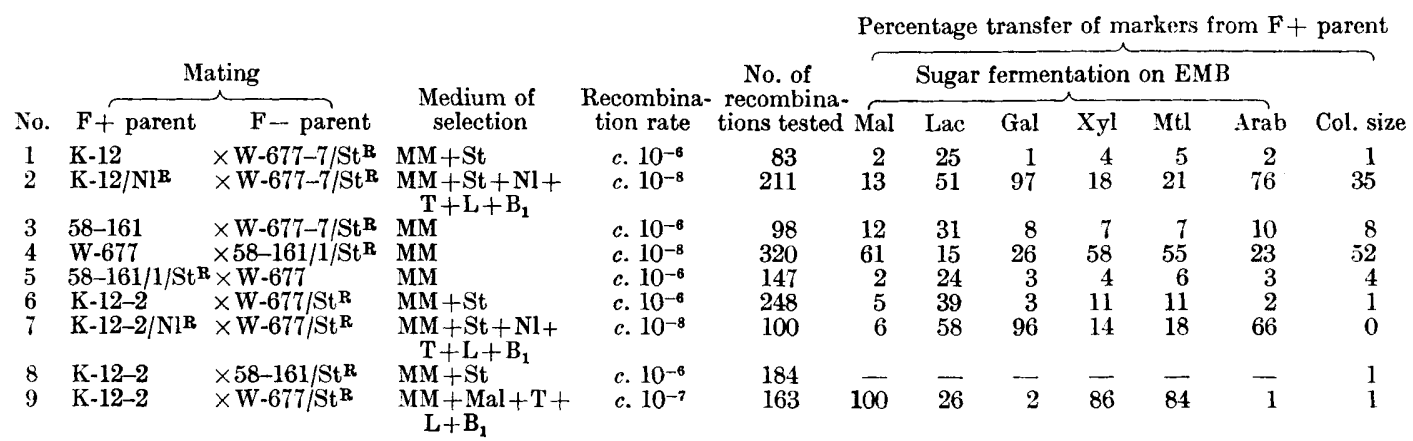

$\mathrm{MM}=$ minimal medium, $\mathrm{St}=$ streptomycin, $\mathrm{Nl}=$ norleucine $\mathrm{T}=$ threonine, $\mathrm{L}=$ leucine, $\mathrm{B}_{1}=$ thiamine, $\mathrm{Lac}=$ lactose, $\mathrm{Mal}=$ maltose, Gal =galactose, $\mathrm{Xyl}=\mathrm{xylose}, \mathrm{Mtl}=$ mannitol, Arab $=$ arabinose.

cross between two normal-sized colony parents (Table 3, line 1). The percentage transfer of the colonial character of the $\mathrm{F}+$ parent, in this instance normal size, was $1 \%$. This implied that it is unlikely that the small-colony character of W-677-7 is controlled by cytoplasmic genetic units, because otherwise it would be expected that the colony size of the progeny would be either mostly normal or all small, depending whether cytoplasmic fusion is or is not a necessary preliminary to recombination. The independence of cytoplasmic control is supported by the results of a similar cross where the variant was mated to a norleucine-resistant mutant of Escherichia coli K-12 on MM medium + norleucine $(\mathrm{Nl})+$ threonine $(\mathrm{T})+$ leucine $(\mathrm{L})+$ thiamine $\left(\mathrm{B}_{1}\right)($ Table 2 , line 2). In this cross, by transferring a different part of the $\mathbf{F}+$ chromosome 
(that containing the $\mathrm{Nl}^{\mathrm{R}}$ locus instead of the loci $\mathrm{T}^{+}, \mathrm{L}^{+}$and $\mathrm{B}_{1}^{+}$), not only is the transfer of sugar markers changed (and resembles the pattern from the corresponding normal mating shown in Table 3, line 2), but the percentage of progeny resembling the $\mathbf{F}+$ parent in colonial size is increased from 1 to $35 \%$. If by selecting a different part of the $\mathbf{F}+$ chromosome we alter the percentage transfer of a character, we may infer that the character is determined by a locus on the chromosome; this eliminates the possibility of cytoplasmic control. Moreover, this locus which controls small-colony size is seen to be located in the region of the $\mathrm{Nl}$ locus. In Table 2 , line 3, the mating of this variant with a methionine-requiring $\mathrm{K}-12 E$. coli auxotroph, 58-161/F+, is summarized. The transfer of sugar markers resembles the parallel normal-colony cross

Table 3. Matings of strains of Escherichia coli $K-12$, both parents being of normal-colony size

\begin{tabular}{|c|c|c|c|c|c|c|c|c|c|c|c|}
\hline \multirow[b]{2}{*}{ No. } & \multicolumn{2}{|c|}{ Mating } & \multirow{2}{*}{$\begin{array}{l}\text { Medium of } \\
\text { selection }\end{array}$} & \multirow{2}{*}{$\begin{array}{l}\text { Recombination } \\
\text { rate }\end{array}$} & \multirow{2}{*}{$\begin{array}{l}\text { No. of } \\
\text { recombina- } \\
\text { tions tested }\end{array}$} & \multicolumn{6}{|c|}{$\begin{array}{l}\text { markers of F + parent, } \\
\text { scored on EMB. }\end{array}$} \\
\hline & $\mathbf{F}+$ parent & $\mathbf{F}$ - parent & & & & Mal & Lac & Gal & Xyl & Mtl & Arab \\
\hline $\mathbf{1}$ & K-12 & $\times W-677 / S^{R}{ }^{R}$ & $\mathbf{M M}+\mathbf{S t}$ & c. $10^{-6}$ & 226 & 4 & 26 & 1 & 13 & 12 & $\mathbf{0}$ \\
\hline 2 & $\mathrm{~K}-12 / \mathrm{Nl}^{\mathrm{R}}$ & $\times \mathbf{W}-677 / \mathbf{S t}^{\mathrm{R}}$ & $\begin{array}{c}\mathbf{M M}+\mathbf{S t}+\mathbf{N l}+ \\
\mathbf{T}+\mathbf{L}+\mathbf{B}_{1}\end{array}$ & c. $10^{-8}$ & 184 & 15 & 38 & 93 & 27 & 26 & 73 \\
\hline 3 & $58-161$ & $\times W-677 / S^{R}$ & $\mathbf{M M}$ & c. $10^{-6}$ & 240 & 6 & 27 & 4 & 12 & 12 & 5 \\
\hline 4 & W-677 & $\times 58-161 / \mathrm{St}^{\mathrm{R}}$ & $\mathbf{M M}$ & c. $10^{-6}$ & 412 & 21 & 4 & 8 & 26 & 25 & 7 \\
\hline 5 & K-12 & $\times 58-161 / \mathrm{St}^{\mathrm{R}}$ & $\mathbf{M M}+\mathbf{S t}$ & c. $10^{-6}$ & - & - & - & - & - & 一 & - \\
\hline
\end{tabular}

(Table 3, line 3) and $8 \%$ of the progeny resemble the $\mathrm{F}+$ parent in having normal colonial size. Although in this cross we are also selecting the loci $\mathbf{T}^{+}$, $\mathrm{L}^{+}$and $\mathrm{B}_{1}+$ from the $\mathbf{F}+$ parent (as in Table 2, line 1 ) the 'contra-selected' marker (Clowes \& Rowley, 1954b) in this instance is $\mathbf{M}^{-}$instead of $\mathrm{St}^{\mathbf{s}}$. That the percentage transfer of colonial size is increased suggests that the locus controlling this character is more closely linked to St than to $\mathbf{M}$, and from the mating shown in Table 2, line 2, lies even closer to the Nl locus.

Matings involving other small-colony variants do not lend themselves to such a simple genetic interpretation. In Table 2 , line 4 , results of the mating of $58-161 / 1 / \mathrm{St}^{\mathrm{R}} / \mathrm{F}-$, a small-colony variant of $58-161 / \mathrm{St}^{\mathrm{R}} / \mathrm{F}-$, with $\mathrm{W}-677 /$ $\mathbf{F}+$ on MM medium is shown. Here not only is the recombination rate only $2 \%$ of that found in the parallel large colony cross (Table 3, line 4), but among the progeny there is a much larger percentage transfer of sugar markers. Consequently, the appearance of $\mathbf{5 2} \%$ large colonies among the recombinants cannot be interpreted as being due to a simple transfer of a gene linked to the $\mathrm{M}+$ locus. When 58-161/1 was made $\mathrm{F}+$ it recombined normally with $\mathrm{W}-6 \mathrm{67} /$ F - (Table 2, line 5), the recombination rate and percentage transfers of unselected markers paralleling the normal 58-161/F $+\times W-677 F-$ cross (Table 3, line 3 ). Since $4 \%$ of the progeny were of small colonial size, this again suggests that the variant did not arise as a result of cytoplasmic variation. The other small-colony variant of 58-161, 158-161/2 behaved like 58-161/1. It was therefore thought to be the same strain, and the results of its matings are pooled with those of $58-161 / 1$. 
The small-colony variants of Escherichia coli K-12, namely K-12-1 and K-12-2, were mated with various auxotrophs. Both strains behaved similarly with regard to the recombination rate, and in the percentage transfer of unselected markers, and were thus assumed to be identical, the results being accordingly pooled. The matings of K-12-2 (or K-12-1) are shown in Table 2, lines 6-9. Its recombination rate and sugar transfer were normal (cf. Table 3, lines 1,2 and 5 ), but whether the loci, $\mathrm{T}^{+}, \mathrm{L}^{+}, \mathrm{B}_{1}{ }^{+}$or $\mathrm{Nl}^{\mathrm{R}}$ or $\mathrm{M}^{+}$were selected there was little or no transfer of the small colony character. This might be due to the linkage of the locus which controls the small colony character with the locus $\mathrm{St}^{\mathrm{s}}$, which must always be selected against because of the prototrophy of this variant. An attempt was made to resolve this possibility by selecting the recombinants from a cross of $\mathrm{K}-12-2$ with $\mathrm{W}-677 / \mathrm{St}^{\mathrm{R}} / \mathrm{F}-$ on $\mathrm{MM}$ medium + maltose in place of glucose +threonine +leucine + thiamine. By this method selection is made for the locus $\mathrm{Mal}^{+}$from the $\mathrm{F}+$ parent which is known to be located very near to the St locus. However, as the results show in Table 2, line 9 , this was not successful in bringing over the small colony character of the $\mathbf{F}+$ parent.

The results shown in Table 2 suggest that the small-colony character is controlled by mutation of one of several nuclear genes, and that the mutations in each strain are non-allelic. This was verified by inter-crossing the smallcolony variants. Table 4 shows that, under these circumstances, it is possible to obtain progeny of large-colony size by mating any two of the small-colony variants under the appropriate conditions of selection.

Table 4. Intercrosses of small-colony variants of Escherichia coli $K-12$ and its auxotrophs

\begin{tabular}{|c|c|c|c|c|c|}
\hline \multirow[b]{2}{*}{ No. } & \multicolumn{2}{|c|}{ Mating } & \multicolumn{2}{|r|}{$\begin{array}{c}\text { Selected } \\
\text { markers from }\end{array}$} & \multirow{2}{*}{$\begin{array}{c}\text { Percentage } \\
\text { progeny of } \\
\text { normal colonial } \\
\text { size }\end{array}$} \\
\hline & $\mathbf{F}+$ parent & $F-$ parent & Medium of selection & F + parent & \\
\hline 1 & K-12-2 & $\times W-677 / 7 / 7 \mathrm{St}^{\mathrm{R}}$ & $\mathbf{M} \mathbf{M}+\mathbf{S t}$ & $\mathbf{T}^{+} \mathbf{L}+\mathbf{B}^{+}{ }_{1}$ & 0 \\
\hline 2 & $\mathrm{~K}-12-2 / \mathrm{Nl}^{\mathrm{R}}$ & $\times \mathrm{W}-677 / 7 / \mathrm{St}^{\mathrm{R}}$ & $\begin{array}{c}\mathbf{M M}+\mathrm{St}+\mathbf{N I}+ \\
\mathbf{T}+\mathbf{L}+\mathbf{B}_{1}\end{array}$ & $\mathrm{NI}^{\mathrm{R}}$ & 28 \\
\hline 3 & $\mathrm{~K}-12-2$ & $\times 58-161 / 1 / \mathrm{St}^{\mathrm{B}}$ & $\mathbf{M M}+\mathbf{S t}$ & $\mathbf{M}^{+}$ & 15 \\
\hline 4 & $\mathrm{~W}-677 / 7 / \mathrm{St}^{\mathrm{B}}$ & $\times 58-161 / 1 / \mathrm{St}^{\mathrm{B}}$ & $\mathbf{M M}$ & $\mathbf{M}^{+}$ & 38 \\
\hline $\mathbf{5}$ & $58-161 / 1 / \mathrm{St}^{\mathrm{R}}$ & $\times W-677 / 7 / S^{R}$ & $\mathbf{M M}$ & $\mathbf{T}+\mathbf{L}+\mathbf{B}_{1}$ & 5 \\
\hline
\end{tabular}

The speeds of movement of recombinants from the mating of $\mathrm{K}-12 / \mathrm{Nl}^{\mathrm{R}} / \mathrm{F}+$ (which has a relatively high speed of movement and has a relatively large colony size) with $\mathrm{W}-\mathbf{6 7 7 - 7} / \mathrm{St}^{\mathrm{R}} / \mathrm{F}$ - (which has a slower speed of movement and a smaller colony size) which appeared on $\mathbf{M M}$ medium $+\mathrm{St}+\mathrm{Nl}+\mathbf{T}+\mathrm{L}+$ $B_{1}$ were determined by the capillary method. In this mating, where the $\mathbf{F}+$ parent has the characters high speed and large colony and the $\mathrm{F}$ - parent slow speed and small colony, it is seen from Table 2, line 2, that some recombinants are small and some are large, owing to the transfer of the locus for large-colony size from the $\mathbf{F}+$ parent to the $\mathrm{F}$ - parent. However, when large and small recombinants were examined, both fast and slow speeds of movement were found in each class. 


\section{DISCUSSION}

A fundamental difficulty in attempting to identify the origin of small-colony variants has been the great diversity in the properties of the variants isolated. Lindegren (1935) suggested that the methods of isolation and properties of small-colony variants isolated by certain workers could be explained by a 'transgenation', a mutation at a circumscribed locus on the genetic material; this view was supported by Braun (1947). From the present study, the resemblance of the small-colony variants isolated from Escherichia coli K-12 and its auxotrophs to the original normal-sized colony strains in all characters, other than rate of multiplication, suggests that they may be of the kind postulated by Lindegren, and have arisen as a result of the mutation of a single nuclear gene. In particular the genetic studies with the variant W-677-7 seem to support this conclusion.

The recombination results of the other variants (58-161/1 and K-12-1) do not allow such simple inferences. In recombinations with $58-161 / 1$ as the $F-$ parent, the rate of recombination is lower and the transfer of $\mathbf{F}+$ markers to the recombinants is greater than in corresponding crosses with the normalsized colony parent. This suggests that additional loci from the $\mathbf{F}+$ parent must be transferred to yield prototrophic recombinants, and points to a growth requirement for the small-colony variant in addition to that required by the parent strain. However, since strain 58-161/1 will grow on MM medium supplemented with methionine, the zygote derived from the 58-161/1 cell would be expected to grow on MM medium, albeit more slowly, when only the $\mathrm{M}^{+}$locus was transferred from the $\mathbf{F}+$ parent, and this would give a predominance of small-colony progeny. It appears therefore that there is some interference with the ability of 58-161/1 to fulfil the role of gene acceptor.

It has been shown by matings involving K-12-2 that selection for the genetic loci investigated, which cover all the well-studied parts of the K-12 chromosome, does not result in transfer of the small-colony character to any significant degree. Therefore it must be concluded that if this character is controlled by a nuclear genetic locus, either the locus is very strongly linked with the St locus, which is necessarily a 'contra-selected' F + marker in these matings, or it lies on some part of the chromosome that is not transferred, either because of its remoteness from the selected markers or its proximity to a possible constant point of elimination. Nuclear control has, however, not been clearly demonstrated in this instance because of our inability to vary the amount of transfer of this small-colony character by selecting loci in different regions of the chromosome.

It seems likely from the segregation of colonial size and speed of movement found in the recombinants of certain matings, that these two characters are not controlled by the same gene. However, the results do not allow differentiation of cytoplasmic or nuclear control of speeds of movement. Differences in speeds were reported by Ogiuti (1936), who found from direct observation of the microscope field that whereas all strains of most motile species had the same speeds, in Escherichia coli there was a twofold inter-strain variation. 
Of two of our strains examined under the microscope, one strain, characterized as a fast swimmer by the capillary method, was well flagellated and had a high population of motile cells, whereas the other, characterized as a slow swimmer, had fewer motile individuals and a smaller number of flagella/ cell. The flagellar wavelength in the two strains was 2.53 and $2.51 \mu$ respectively (Dr E. Leifson, personal communication).

The effect of $\mathrm{CuSO}_{4}$ on Escherichia coli in the production of small-colony variants was interpreted as an inductive process by Weed \& Longfellow (1954) who found that a population of $c .150$ cells of $\boldsymbol{E}$. coli $\mathrm{B}$ gave rise to smallcolony variants in an inhibitory concentration of copper. It was suggested that simple selection of spontaneous mutants would not explain this phenomenon, although the small-colony variants were more resistant to the concentration of copper used in the isolation than was the original strain. The inductive effect of copper was compared with the effect of acriflavine on yeast which Ephrussi (1953) ascribed to an interference with reproduction of cytoplasmic genetic units. However, in the isolation of the small-colony variants described in the present paper, these variants were isolated from cultures at the threshold of inhibition and the variants so isolated did not have any greater resistance to the bactericidal action of copper. In most instances the conditions of isolation do not exclude their origin by spontaneous mutation at a rate of about $10^{-5} /$ cell division.

The slower rate of cell-division in liquid medium and on most solid media, and in particular on a partially defined medium as in MM medium, suggests that the variant does not differ by the requirement for a growth factor but by some non-specific factor such as a variation in the permeability of the cell wall to most nutrients. However, the ability to vary the size ratios illustrated by the larger size of the small-colony variants on veal digest + glucose agar and the smaller size of the original strains on PLYP agar (both compared with nutrient agar) might indicate that some growth factor, as yet unidentified, is present in suboptimal amounts in these media.

Many of the properties of small-colony variants can be accounted for by an overall lowering in the metabolic rate, as suggested by Youmans (1937). This explanation might account for the isolation of many of these variants from toxic environments, in which the inhibitor permeated the small-colony variants at a lower rate and thus permitted their survival for longer than the corresponding, normally metabolizing organisms. This general lowering of the metabolic rate might conceivably be due to a decrease in cell wall permeability.

We are indebted to Dr Einar Leifson of Loyola University for photomicrographic studies, to Dr G. Furness for help with working out the motility measurement method, to Dr C. E. Challice for electron micrographs, to the Photographic Department, St Mary's Hospital Medical School, and to Miss Judith Battle and Mr W. Peden for technical assistance. 


\section{REFERENCES}

Braun, W. (1947). Bacterial dissociation. Bact. Rev. 11, 75.

Challice, C. E. \& Gorrill, R. H. (1954). Some observations on the morphological changes in $E$. coli accompanying induction by ultra violet light. Biochem. biophys. Acta, 14, 482 .

Clowes, R. C. \& Rowley, D. (1954a). Genetic investigation of the inhibition by DL-norleucine of the K-12 strain of Escherichia coli. J. gen. Microbiol. 11, 27.

Clowes, R. C. \& Rowley, D. (1954b). Some observations on linkage effects in genetic recombination in Escherichia coli K-12. J. gen. Microbiol. 11, 250.

Cohen, S. M. \& Wheeler, M. W. (1946). Pertussis vaccine prepared with phase I cultures grown in fluid medium. Amer. J. publ. Hlth, 36, 371.

Colwell, C. A. (1946). Small colony variants of Escherichia coli. J. Bact. 52, 417.

Davis, B. D. \& Mingloli, E. S. (1950). Mutants of Escherichia coli requiring methionine or vitamin B12. J. Bact. 60, 17.

Ephrussi, B. (1953). Nuclear-Cytoplasmic Relations in Micro-Organisms. Oxford: Clarendon Press.

Furness, G. \& Rowley, D. (1955). Transfer of motility from Escherichia coli K-12 to $E$. coli B. J. gen. Microbiol. 12, v.

Gillespie, W. A. (1952). Biochemical mutants of coliform bacilli in infections of the urinary tract. J. Path. Bact. 64, 551.

Hadley, P., Delves, E. \& Klimek, J. (1931). The filterable forms of bacteria. I. A filterable stage in the life history of the Shiga dysentery bacillus. $J$. infect. Dis. 48, 1.

HALE, J. H. (1951). Studies on staphylococcus mutation: A naturally occurring ' $G$ ' gonidial variant and its carbon dioxide requirements. Brit. J. exp. Path. 32, 307.

HaYes, W. (1953). Observations on a transmissible agent determining sexual differentiation in Bacterium coli. J. gen. Microbiol. 8, 72.

Hiluier, J. \& BAKer, R. F. (1946). The mounting of bacteria for electron microscope examination. J. Bact. 52, 411.

Kuhn, P. \& Sternberg, K. (1931). Über Bakterien und Pettenkoferien. Zbl. Bakt. $121,113$.

LEDERBERG, J. (1950). Isolation and characterization of biochemical mutants. Meth. med. Res. 3, 5.

Lederberg, J. (1951). Prevalence of Escherichia coli strains exhibiting genetic recombination. Science, 114, 68.

Lederberg, J. \& Lederberg, E. M. (1952). Replica plating and indirect selection of bacterial mutants. J. Bact. 63, 399.

LINDEGREN, C. C. (1935). Genetic studies on bacteria: III. Origin of G-type colonies by transgenation. Zbl. Bakt. 93, 389.

Manten, A. \& Rowley, D. (1953). Influence of chloramphenicol and specific antiserum on the variability of the K-12 strain of Bact. coli. Brit. J. exp. Path. 34, 23.

Mazloum, H. A. \& Rowley, D. (1955). The growth requirements of Haemophilus pertussis on solid media. J. Path. Bact. (in the Press).

Mires, A. A. \& MrsRA, S. S. (1938). The estimation of the bactericidal power of the blood. J. Hyg., Camb. 38, 732.

OGruTI, K. (1936). Untersuchungen über die Geschwindigkeit der Eigenbewegung von Bakterien. Jap. J. exp. Med. 14, 19.

Rowley, D. (1953). Inter-relationships between amino-acids in the growth of coliform organisms. J. gen. Microbiol. 9, 37.

Swingle, E. L. (1934). Studies on small colony variants of Staphylococcus aureus. Proc. Soc. exp. Biol., N.Y. 31, 891. 
Journal of General Microbiology, Vol. 13, No. 3
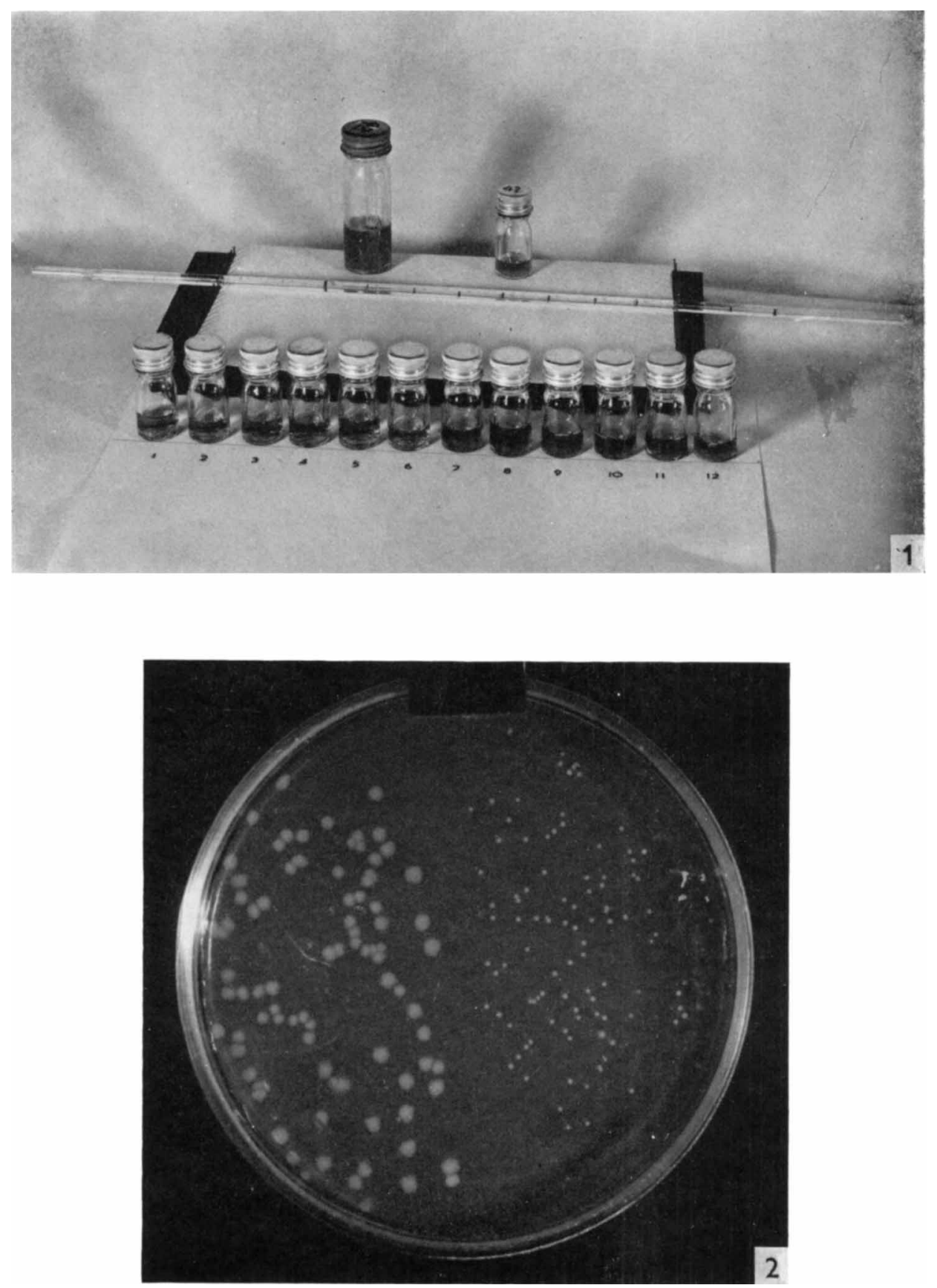

R. C. Clowes \& D. Rowley-Small-Colony variants of E. coll. Plate 1 
Swingle, E. L. (1935). Studies on small colony variants of Staphylococcus aureus. J. Bact. 29, 467.

TAYLOR, C. B. (1950). An improved method for the preparation of silica gel media for microbiological purposes. J. gen. Microbiol. 4, 235.

VoureKA, A. (1951). Bacterial variants in patients treated with chloramphenicol. Lancet, i, 27.

VourekA, A. (1952). Induced variations in a penicillin-resistant staphylococcus. J. gen. Microbiol. 6, 352 .

Weed, L. L. \& Longfellow, D. (1954). Morphological and biochemical changes induced by copper in a population of Escherichia coli. J. Bact. 67, 27.

WEINBERG, E. D. (1950). Vitamin requirements of dwarf colony variants of bacteria. J. infect. Dis. 87, 299.

Wilkinson, J. F., Duguid, J. P. \& Edmunds, P. N. (1954). The distribution of polysaccharide production in Aerobacter and Escherichia strains and its relation to antigenic character. J. gen. Microbiol. 11, 59.

WISE, R. I. \& SpINK, W. W. (1954). Influence of antibiotics on the origin of small colonies (' $G$ ' variants) of Micrococcus pyogenes var. aureus. J. clin. Invest. 33, 1611.

Youmans, G. P. (1937). Production of small-colony variants of Staphylococcus aureus. Proc. Soc. exp. Biol., N.Y. 36, 94.

\section{EXPLANATION OF PLATE}

Fig. 1. Apparatus used in the determination of speeds of motility.

Fig. 2. Growth of Escherichia coli K-12 and small colonial variant on nutrient agar for $18 \mathrm{hr}$. at $37^{\circ}$. (Left-hand side parent K-12; right-hand side variant K-12-1). 